J. Clin. Chem. Clin. Biochem.

Vol. 16,1978 , pp. $187-189$

\title{
A Specific Detection Method for Multiple Forms of Cystine Aminopeptidase (Oxytocinase- Isoenzymes) after Polyacrylamide Gel Electrophoresis
}

\author{
By T. van Buul and A. P. M. van Oudheusden
}

Department of Clinical Chemistry, Sint Jozef Ziekenhuis, NL-7000 AD Doetinchem, The Netherlands

(Received August 3/September 19, 1977)

Summary: A simple and specific detection method for multiple forms of cystine aminopeptidase (oxytocinaseisoenzymes) in pregnancy serum is described using S-benzyl- $L$-cysteine-p-nitroanilide as substrate. The relative distribution of both cystine aminopeptidase isoenzymes at different stages of pregnancy is given.

Eine spezifische Methode zum Nachweis der multiplen Formen von Cystin-Aminopeptidase (Oxytocinase-Isoenzyme) nach Polyacrylamidgel-Elektrophorese

Zusammenfassung: Es wird eine einfache und spezifische Methode zum Nachweis der multiplen Formen von Cystin-Aminopeptidase (Oxytocinase-Isoenzyme) im Serum Schwangerer unter Verwendung von S-Benzyl- $L$ cystein-p-nitroanilid als Substrat beschrieben. Die relative Verteilung der beiden Cystin-Aminopeptidase-Isoenzyme in verschiedenen Perioden der Schwangerschaft wird mitgeteilt.

\section{Introduction}

The detection methods for oxytocinase-isoenzymes (cystine aminopeptidase 1 and 2) (EC 3.4.11.3) in pregnancy serum after polyacrylamide gel electrophoresis using $L$-leucine- $\beta$-naph thylamide as substrate are non-specific $(1,2,3)$. Both cystine aminopeptidase 1 and 2 and leucine aminopeptidase activity (EC 3.4.11.2) are always detected. Using $L$-cystine-di- $\beta$-naphthylamide as substrate, only the cystine aminopeptidase isoenzymes are demonstrated (4), but both bands on the gel are too faint for scanning. Moreover, $\beta$-naphthylamides are carcinogenic.

$L$-Cystine-bis-p:nitroanilide and S-benzyl: $L$ :cysteine$p$-nitroanilide are split only by oxy tocinase, but in the assay of oxytocinase the first substrate is less sensitive than S-benzyl- $L$-cysteine- $p$-nitroanilide (5). We therefore propose a new specific detection method for cystine aminopeptidase 1 and 2 , using a substrate that does not have these disadvantages: $S$-benzyl- $L$-cysteine$p$-nitroanilide (6). After electrophoresis the liberated $p$-nitroaniline is diazotized during the enzymatic reaction, then coupled with $\mathrm{N}$-(1-naphthyl)-ethylenediamine to yield pink coloured bands (7).

\section{Materials and Methods}

The separation of cystine aminopeptidase isoenzymes is based on the method of 1.c. (1).

To achieve good and reproducible separation of both isoenzymes we have adopted a $75 \mathrm{~g} / 1$ acrylamide concentration in the separation gel and $0.078 \mathrm{~mol} / 1$ borate buffer $\mathrm{pH} 8.6$.

Polyacrylamide gel electrophoresis was carried out with a

Canalco Research Disc Electrophoresis Equipment model 1200

and a Electrophoresis Constant Rate Source model 100 for $1.5 \mathrm{~h}$ at $0^{\circ} \mathrm{C}(5 \mathrm{~mA} / \mathrm{gel})$. The detection of the isoenzymes is performed as follows.

Reagents for the detection of cystine aminopeptidase isoenzymes

1. Dissolve $26 \mathrm{mg}$ S-benzyl- $L$-cysteine-p-nitroanilide (Boehringer Mannheim or British Drug House) in $20 \mathrm{ml}$ 2-methoxyethanol $(4 \mathrm{mmol} / \mathrm{l})$. Store in a brown bottle at $4^{\circ} \mathrm{C}$.

2. Citrate-phosphate buffer $\mathrm{pH}$ 6.0. $\mathrm{Mix} 36.8 \mathrm{ml}$ of $0.1 \mathrm{~mol} / \mathrm{l}$ citric acid with $63.2 \mathrm{ml}$ of $0.2 \mathrm{~mol} / 1 \mathrm{Na}_{2} \mathrm{HPO}_{4}$-solution. Store at $4^{\circ} \mathrm{C}$.

3. Dissolve $50 \mathrm{mg} \mathrm{NaNO}$ and $10 \mathrm{mg} \mathrm{N}$-(1-naphthyl)-ethylenediamine $-2 \mathrm{HCl}$ (J. T. Baker Chemicals) in $50 \mathrm{ml}$ reagent 2 at $37^{\circ} \mathrm{C}$. Prepare before use.

4. Incubation reagent. Add reagent 1 to reagent 3 in a ratio $30 \mathrm{ml}+70 \mathrm{ml}$.

5. Dissolve $125 \mathrm{~g}$ trichloroacetic acid in 11 water.

Proposed detection-method

After electrophoresis incubate the gels in the incubation reagent for $1 \mathrm{~h}$ at $37^{\circ} \mathrm{C}$. Wash the gels $1 \mathrm{~min}$ with water to remove excess $\mathrm{NaNO}_{2}$ and substrate. 
Incubate the gels $1 \mathrm{~min}$ in reagent 5. Scanning of the gels was performed with a densitometer Kipp Skalar Densiscan KS 3 filter $530 \mathrm{~nm}$ and $\mathrm{XY}$-Recorder BD 22.

The total serum oxytocinase catalytic concentration was determined kinetically (5).

\section{Results and Discussion}

After incubating the gels in the incubation reagent two strong pink bands were obtained (Fig. 1). The intensity of the pink bands became maximal 5-6 min after treatment with trichloroacetic acid and remains constant for $1 \mathrm{~h}$. In sera with low levels of total oxytocinase catalytic concentration (12-19 U/1) the first isoenzyme to appear, i. e. cystine aminopeptidase 1 , can be easily detected. In a serum with a total oxy tocinase catalytic concentration of $37 \mathrm{U} / 1$ both the cystine aminopeptidase isoenzymes $\left(\mathrm{CAP}_{1}\right.$ and $\left.\mathrm{CAP}_{2}\right)$ can be readily demonstrated $\left(\mathrm{CAP}_{1} 61 \%\right.$ and $\mathrm{CAP}_{2} 39 \%$ of the total activity). In late pregnancy sera (total oxy tocinase catalytic concentration 115-144 U/1) the activity of cystine aminopeptidase 2 is in general greater than the activity of cystine aminopeptidase 1: $\mathrm{CAP}_{1} 37-44 \%$ and $\mathrm{CAP}_{2}$ 56-63\% of the total activity (Fig. 2).

From the literature $(1,2,3)$ it is not clear which isoenzyme appears first in the serum during pregnancy. Kleiner \& Brouet-Yager (4) stated that cystine aminopeptidase 2 is the first isoenzyme to appear. We could not confirm this. Preliminary results with our detection method show that cystine aminopeptidase 1 is the earliest demonstrable isoenzyme.

The relative electrophoretic mobilities of the cystine aminopeptidase isoenzymes 1 and 2 are: $0.60 \pm 0.01$

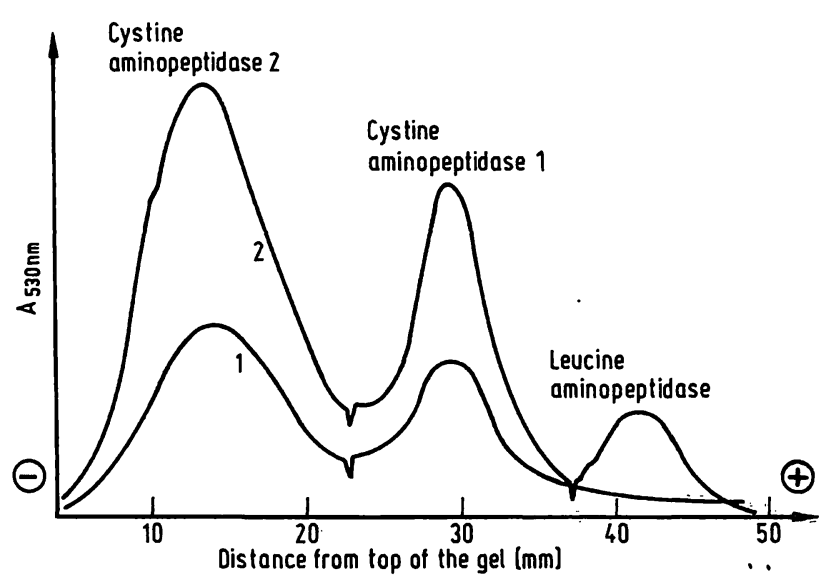

Fig. 1. Detection of cystine aminopeptidase isoenzymes 1 and 2 $\left(\mathrm{CAP}_{1}\right.$ and $\left.\mathrm{CAP}_{2}\right)$.

1. Our detection method, substrate S-benzyl- $L$-cysteinep-nitroanilide $(4 \mathrm{mmol} / \mathrm{l})$.

2. Detection method according to l. c. (1), substrate $L$-leucine- $\beta$-naphthylamide $(4 \mathrm{mmol} / \mathrm{l})$. Total serum oxytocinase catalytic concentration $116 \mathrm{U} / 1$.

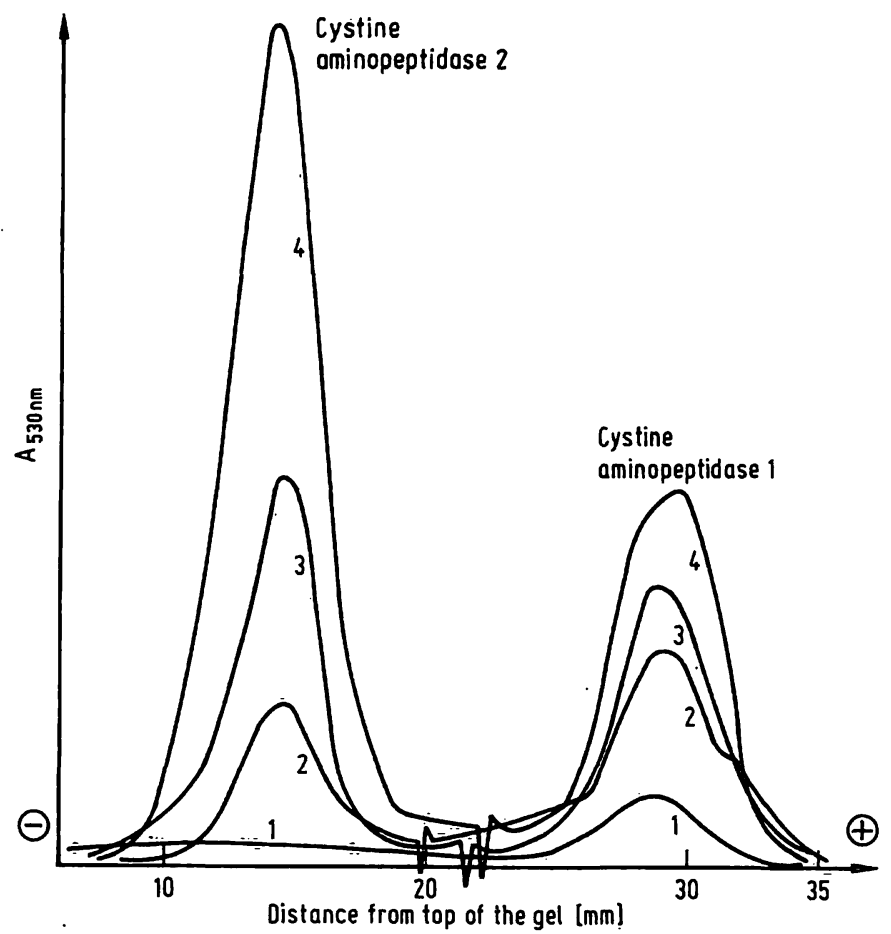

Fig. 2. Relative distribution of the cystine aminopeptidase isoenzymes 1 and $2\left(\mathrm{CAP}_{1}\right.$ and $\left.\mathrm{CAP}_{2}\right)$ in sera of different pregnant women.

1. Total serum oxytocinase catalytic concentration $14 \mathrm{U} / 1 ; \mathrm{CAP}_{1} 100 \%, \mathrm{CAP}_{2} 0 \%$.

2. Total serum oxytocinase catalytic concentration $37 \mathrm{U} / 1 ; \mathrm{CAP}_{1} 61 \%, \mathrm{CAP}_{2} 39 \%$.

3. Total serum oxytocinase catalytic concentration $76 \mathrm{U} / \mathrm{l} ; \mathrm{CAP}_{1} 49 \%, \mathrm{CAP}_{2} 51 \%$.

4. Total serum oxytocinase catalytic concentration $144 \mathrm{U} / 1 ; \mathrm{CAP}_{1} 37 \%, \mathrm{CAP}_{2} 63 \%$.

(Sensitivity in Y-direction is greater than in fig. 1).

and $0.26 \pm 0.02(\mathrm{x} \pm \mathrm{SD}, \mathrm{N}=10)$ respectively, using bromophenol blue as tracking dye.

In contrast with Tovey et al (8) we could not observe any influence on the intensity of the $\mathrm{CAP}_{1}$ and $\mathrm{CAP}_{2}$ bands, when varying the 2-methoxyethanol concentration from 100 to $300 \mathrm{ml} / 1$ in the incubation-reagent. We used a $300 \mathrm{ml} / 1$ 2-methoxyethanol concentration, because of the solubility of S-benzyl- $L$-cysteine- $p$ nitroanilide. The concentrations of $\mathrm{NaNO}_{2}$ and $\mathrm{N}$ (1-naphthyl)-ethylenediamine given by (7) were too high, resulting in a turbid incubation reagent. We decreased these concentrations to give final concentrations of $10 \mathrm{mmol} / 1$ and $0.5 \mathrm{mmol} / 1$ for $\mathrm{NaNO}_{2}$ and $\mathrm{N}$-(1-naphthyl)-ethylene-diamine respectively, which gave a clear incubation reagent when dissolved at $37^{\circ} \mathrm{C}$.

Further studies on the relative distibution of the cystine aminopeptidase isoenżymes in normal and high risk pregnancy sera are in progress.

\section{Acknowledgement}

We thank Miss $A$. R. Verhoef for her skillful technical assistance. 


\section{References}

1. Kleiner, H. \& Schram, E. (1966), Clin. Chim. Acta 14, 377-385.

2. Oya, M., Yoshino, M. \& Asano, M. (1974), Experientia 30, 985-986.

3. Mizutani, S., Yoshino, M. \& Oya, M. (1976), Clin. Biochem. 9, 16-18.

4. Kleiner, H. \& Brouet-Yager, M. (1972), Clin. Chim. Acta $40,177-180$.
5. Van Buul, T. \& van Oudheusden, A. P. M. (1974), Clin. Chim. Acta 54, 263-268.

6. Van Oudheusden, A. P. M. (1972), J. Clin. Chem. Clin. Biochem. 10, 345-346.

7. Dahlmann, B. \& Jany, K. D. (1975), J. Chromatogr. 10, 174-177.

8. Tovey, J. E., Dawson, P. J. G. \& Fellowes, K. P. (1973), Clin. Chem. 19, 756-761.
Dr. T. van Buul

Department of Clinical Chemistry

Sint Jozef Ziekenhuis

NL-7000 AD Doetinchem

The Netherlands 


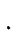

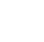

-

